\title{
Para valorizar a dimensão da vida cotidiana: articulações ao debate das sustentabilidades
}

\section{To value the dimension of everyday life: articulations to the debate on sustainability}

\author{
Valorar la dimensión de la vida cotidiana: articulaciones al debate de la sostenibilidad
}

Gabriel dos Santos Martins ${ }^{1}$ : https://orcid.org/0000-0001-9940-5136

\footnotetext{
${ }^{1}$ Mestrando em Geografia do Programa de Pós-Graduação (POSGEO) - Pontifícia Universidade Católica do Rio de Janeiro - Bolsista da CAPES - Membro do Grupo de Estudos Urbanos e Rurais (URAIS) - gabrieldossantosmartins @ yahoo.com.br
}

\begin{abstract}
Resumo
Propomos a valorização da dimensão do cotidiano enquanto enfoque de análise que exerce importância para o debate que constrói a necessidade de novos padrões de sustentabilidades frente às segregações socioambientais. A discussão ambiental comumemente está relacionada ao privilégio das grandes dimensões, dos grandes eventos (catástrofes) ambientais, relacionadas aos resultados sociais advindos dos mesmos. A supervalorização de tais processos são entendidos, aqui, enquanto produtores de alienações que negam e camuflamam processos de injustiças ambientais promovidas no dia-a-dia. Valorizar o cotidiano, nos embasamentos de Lefebvre e Heller, para a compreensão mais sólida da realidade, se faz de suma importância para entrelaçar redes e propostas de sustentabilidades que privilegiam o plano da vida comum, a autonomia territorial e a participação ativa dos sujeitos.
\end{abstract}

Palavras-chave: Vida Cotidiana. Sustentabilidades. Socionatureza.

\begin{abstract}
We propose to value the dimension of everyday life as an analysis focus that plays an important role in the debate that builds the need for new standards of sustainability in the face of socio-environmental segregations. The environmental discussion is usually related to the privilege of large dimensions, of major environmental events (catastrophes), related to the social results arising from them. The overvaluation of such processes are understood here as producers of alienations that deny and camouflage processes of environmental injustices promoted on a daily basis. Valuing everyday life, based on Lefebvre and Heller, for a more solid understanding of reality, is of paramount importance to intertwine networks and sustainability proposals that privilege the common life plan, territorial autonomy and the active participation of the subjects
\end{abstract}

Keywords: Everyday Life. Sustainability. Socionature.

\section{Resumen}

Proponemos valorar la dimensión de la vida cotidiana como un enfoque de análisis que juega un papel importante en el debate que construye la necesidad de nuevos estándares de sostenibilidad frente a las segregaciones socioambientales. La discusión ambiental generalmente se relaciona con el privilegio de grandes dimensiones, de grandes eventos ambientales (catástrofes), relacionados con los resultados sociales derivados de ellas. La sobrevaloración de tales procesos se entiende aquí como productores de alienaciones que niegan y camuflan procesos de injusticias ambientales promovidos a diario. Valorar la vida cotidiana, 
MARTINS, G. S.

basada en Lefebvre y Heller, para una comprensión más sólida de la realidad, es de suma importancia para entrelazar redes y propuestas de sostenibilidad que privilegien el plan de vida común, la autonomía territorial y la participación activa de los sujetos.

Palabras clave: La vida cotidiana. La sostenibilidad. La sociedad.

Recebido em: 31/01/2020

Aceito para publicação em: 31/03/2020

\section{Introdução}

O que colocamos nesse escrito é a possibilidade de se considerar a dimensão do cotidiano para subsidiar as concepções formuladas acerca do quadro desenhado a partir da leitura da crise ambiental (que se apresenta enquanto crise societária, de seus valores, ideologias, padrões de produção e conjunto de relações). A (in)gerência de preposições que privilegiam unicamente a escala global tem a máxima de um padrão caótico genérico com premissas regidas pelas catástrofes ambientais globais ou de grande impacto regional. A leitura se embasa, por exemplo, nas catástrofes climáticas (fortemente anunciados nas últimas décadas por agentes, organismos e instituições).

A afirmação recorrente de tal leitura consolidou um campo figurativo cercado por quadros e possibilidades que aprisionam, para o senso comum, uma única escala das injustiças socioambientais, a global. Tal concepção pode ser entendida como uma 1) rede de sentidos que funcionam como uma camisa de força para o entendimento das multiescalaridades dos processos de expropriação e exploração da vida, e como 2) concepção que tende a reduzir e a subestimar de potencialidades das ações locais e regionais, ferindo articulações autônomas, como se as problemáticas ambientais pudessem apenas ser resolvidas pelas grandes ONGs e instituições oficiais internacionais/multilaterais.

Por meio de um evento ambiental de grande espetáculo ressoa que não apenas os mais pobres, os vulnerabilzados, sofrem com o (des)amparo do Estado que privilegia a lógica desenvolvimentista frente à vida, mas tomado como algo de interesse e culpa de todos, sem ideologias, pois o "interesse ambiental é comum e independente das classes sociais". Ou seja, apesar do que se apresenta nos canais midiáticos sobre os impactos de algum desastre à vida, a indiginação e a revolta comum se mesclam com uma indignação que não canaliza os olhares 
e atenção para os reais motivos dos impactos, ligados fortemente com a exclusão e desigualdade social, com a exploração desenfreada da natureza e dos trabalhadores (LAYRARGUES, 2003).

Considerar a dimensão do cotidiano revela traços às negligenciados no debate, que deveriam, na nossa concepção, ser direcionados em pôr em xeque a perspectiva da opressão, da injustiça e da subjugação que transcende aos grandes impactos e desastres ambientais e se materializam no plano da vida, na prática, ao tangível que expressa a totalidade das estruturas engendrada pelas relações sociais. É nessa escala que a genericidade assume o lugar do conjunto de processos que expropriam a natureza e condiciona seres humanos à vulnerabilizados que se faz em extensão dia após dia.

O grande impacto mobiliza atenção e revoltas, estreitando os olhares para a problemática presente, a grande questão da análise reside no fato do tempo passageiro, a indignação repentina se dilui com a vida tomando as suas proporções normais, o cotidiano dilui e fragmenta as revoltas e a transforma em pura mobilização virtual. O cotidiano traz essas diversas dimensões. A angústia é considerada, revemos os padrões analíticos estabelecidos com relação à expropriação da vida. A magnitude dos impactos ambientais está nesse plano e traduz a velocidade máxima do capitalismo, pujante pelo lucro. Mas a vida comum também pode revelar tal verocidade e ser dimensão de privilégio às resistências, mobilizações para renovadas organizações territoriais, novas formas de pensar e praticar as sustentabilidades ressignificadas, bases aqui articuladas com a perspectiva de Rua (2007, 2008).

O artigo que se segue está estruturado em duas partes, onde objetivamos por primeiro intento defender a dimensão cotidiana pela crítica radical filosófica; e segundo, o desenvolvimento analítico das implicações da modernidade para o paradigma sociedadenatureza instaurado, enlaces entre os (des)caminhos do conceito de natureza (PORTOGONÇALVES, 1989) com o desenvolvimeto do capitalismo e a produção das injustiças ambientais advindas desse modelo, para então, falarmos da defesa do enfoque da dimensão do cotidiano para subsidiar a promoção das sustentabilidades.

É no/pelo cotidiano que se guarda a permanência, constituição e disseminação de saberes diversos, que significam a resistência na existência. O que se segue é uma reunição de ideias pensadas a fornecer subsídios teórico-metodológicos para a Geografia envolvida pelas dimensões da vida, da articulação dos saberes e de novos padrões de sociabilidade e produção. 


\section{Notas sobre a valorização do cotidiano}

Ancorados em Agnes Heller (1985), estreitamos nossa análise a considerar as relações entre os valores instituídos historicamente e as representações sobre a natureza que se materializam na vida comum. Cabe pontuar que não é nosso objetivo aqui debruçar sobre a discussão das diferenças dos conceitos e categorias epistemológicas de cada conceito explanado (natureza, ambiente e meio ambiente), não por considerarmos menos importante, mas levando em conta que a nossa proposta pode e deve abranger todas essas formulações, haja vista que os processos de injustiças e segregações socioambientais têm enquanto centralidade diversas prerrogativas analíticas que se articulam com os conceitos e categorias elencadas com os debates entre: natureza, sociedade, produção, desenvolvimento e (meio) ambiente. Optamos pela a utilização da perspectiva de socionatureza de Erik Swyngedouw (2001), que comporta uma estética gráfica que une a formulação filosófica, política e teórica acerca de sociedade e natureza ${ }^{2}$.

Heller (1985, p. 15) pergunta se a história é um processo finalístico, objetivamente teleológico e, responde, afirmando que as alternativas históricas são sempre reais: "sempre é possível decidir, em face delas, de um modo diverso daquele em que realmente se decide. Não era obrigatório que o desenvolvimento social tomasse a forma que tomou; simplesmente foi possível que surgisse essa configuração (ou outra)". O Colapso ambiental global conduzido pela plena realização do capital produtivo e financeiro sobre a vida gera a construção de possibilidades instituindo valores sobre valores, com seu signo na prática material da vida cotidiana. Valores que induzem prerrogativas, anseios e expectativas da realidade, que muitas vezes são postas enquanto caminhos finalísticos para a plena realização do padrão de produção, o que coloca a vida de grupos de pessoas (os vulnerabilizados, os afetados pela lógica da segregação que mantém toda a teia de relações e manutenção do capital) em patamares de subalternidade. Mas no horizonte possível da realização crítico-social, entendemos que estabelecer a possibilidade de um subsequente desenvolvimento dos valores e emprestar um sentido a nossa história, um sentido renovado para a socionatureza, se torna

\footnotetext{
2 “O mundo como um processo histórico-geográfico de perpétuo metabolismo no qual no qual processos sociais e naturais se combinam num processo de produção de socionatureza histórico-geográfico cujo resultado (natureza história) incorpora processos químicos, físicos, sociais, econômicos, políticos e culturais de maneiras altamente contraditórias mas inseparáveis.” (SWYNGEDOUW, 2001, p. 105).
} 
cada vez mais urgente frente a profunda crise socioambiental do tempo presente. Trata-se de uma reelaboração para alternativas históricas inéditas.

E contra generalizações ideológicas sobre os processos de injustiças socioambientais figurados pela formação socioespacial empregada com o modelo capitalista, por que cosiderar a vida cotidiana? Pois, como afirma Heller (1985, p. 20), "A vida cotidiana não está fora da história, mas no centro do contexto histórico: é a verdadeira essência das substâncias sociais". Nossa discussão considera o cotidiano para o desenvolvimento teórico da socionatureza para a promoção de sustentalidades, pois a natureza tomada de forma simplificada e apenas sendo atribuída às grandes catástrofes negligencia os pequenos atos dos homens simples, as ações de expropriação e exploração da vida concreta e prática, do acontecer solidário e resistente. A autora supracitada afirma que a vida cotidiana é vida do indivíduo, por isso considerar uma conceituação sobre o meio ambiente configurado pelas pequenas e grandes relações sociais, que expressam a totalidade e complexidade da dinâmica socioambiental. Nos dizeres de Heller (1985, p. 17), que ensaia filosoficamente a sua preposição em uma construção dialética da vida, aparentemente e efetivamente contraditória:

\begin{abstract}
A vida cotidiana é a vida de todo homem. Todos a vivem, sem nenhuma exceção, qualquer que seja seu posto na divisão do trabalho intelectual e físico. Ninguém consegue identificar-se com sua atividade humano-genérica a ponto de poder desligar-se inteiramente da cotidianidade. E, ao contrário, não há nenhum homem, por mais "insubstancial" que seja, que viva tãosomente na cotidianidade, embora essa o absorva preponderantemente. A vida cotidiana é a vida do homem inteiro; ou seja, o homem participa na vida cotidiana com todos os aspectos de sua individualidade, de sua personalidade. Nela, colocam-se "em funcionamento" todos os seus sentidos, todas as suas capacidades intelectuais, suas habilidades manipulativas, seus sentimentos, paixões, ideias, ideologias.
\end{abstract}

E nesse mesmo plano de realização, o homem da cotidianidade também pode exercer atividade e autonomia para a realização de suas decisões e desejos, onde podemos enquadrar os movimentos resistentes e subversivos de ser e estar no mundo, na construção do que pode vir a ser padrões de socionaturezas mais solidárias e igualitárias, realização através da luta e resistência diária frente à precarização imposta a cada segundo do trabalho alienante. Forma de trabalho que conduz e ataca a vida, e por isso deve ser pauta da discussão ambiental, como elabora Marcuse (apud VISENTINI, 1992, p. 16):

Por que nos ocupamos, então, da ecologia? Porque a violação da Terra é um aspecto essencial da contra-revolução. A guerra, genocídio contra o povo, é também "terricida" na medida em que ataca as fontes e os recursos da 
própria vida [...] Modificar a natureza do homem e o seu meio natural para o "civilizar" - quer dizer, fazer dele o sujeito-objeto da sociedade de troca foi uma das funções essenciais da civilização: subjugar o princípio da realidade, transformar o homem em instrumento de trabalho cada vez mais alienado. Esta transformação brutal, penosa, foi lentamente invadindo a natureza exterior.

A conjuntura requer novos padrões analíticos que considerem as múltipplas escalas em interações. Quadro de injustiças socioambientais do mundo revela amplos e complexos processos simultâneos e interativos. No âmago do debate da socionatureza, o padrão de produção, o trabalho alienante e o cotidiano devem ser considerados na totalidade da expressão do que configuramos e designamos novos padrões de sustentabilidades. A escala do cotidiano é a substância que revela todo o teor da complexidade, que expressa um conjunto de relações, pode (e deve) ser considerada para maior aprofundamento do desvelar da realidade ambiental, o que subsidia a revelação de novas diversas nuances.

O homem imerso na cotidianidade revela tais apreensões e angústias. Partimos de uma compreensão da realidade iminente do movimento dos sujeitos. O cotidiano revela a capacidade criativa e a inventividade dos sujeitos, as táticas que nos interstícios da opressão e subjugação, da segregação e da violência, permitem a continuação da vida. Tratamos aqui não apenas dos movimentos organizados com pautas e mobilizações formais por alguma luta específica. $\mathrm{O}$ ato de resistência a cabo do cotidiano está na vida que consegue ser mantida, existência que permanece quando a realidade ambiental condiciona a própria vida a ser extinguida.

A leitura que paira sobre os movimentos de resistência ambiental se apresentam com foco de alteridade, ações que são respostas a um grande impacto (seja "natural" ou causado por massacres, como latifundiários assassinando povos indígenas). Mas a resistência se mostra diária para aquele que está em condição de vulnerabilidade constante.

Para maior embasamento do que se apresenta, seguimos no próximo item desse ensaio articulando o campo filosófico com a tese que fundamenta o cotidiano, onde articulamos os referenciais da modernidade, seus signos, símbolos e ideologias e a concepção de natureza que daí se constrói, processo atuante para a promoção de desenvolvimentos geográficos desguais, o que ao mesmo tempo demanda a noção de sustenbiliadades aqui utilizada.

\section{Filosofia, ideologia e cotidiano: fundamentos e enfoques às sustentabilidades}

No desenvolvimento das forças produtivas que operam no reino das abstrações, homens e mulheres são tornados homogêneos e pouco a pouco genéricos, e nesse processo, “à 
abstração e ao dinheiro corresponde o nascimento da Razão, entidade metafísica e lógica. Nessa infelicidade da consciência e da realidade humana - e por meio dela - opera-se um progresso" (LEFEBVRE, 1999, p. 163-164). A ideologia que implanta tal progresso atrelado aos padrões de consumo (legitimadas por essa Razão) figuram os pensamentos e corpos que produz desejos e anseios. Para tal, seu movimento deve se apresentar fragmentado, pois a totalidade traduzida traria os enclaves desse padrão de desenvolvimento, há formas degradantes e desumanas que tornam possíveis a realização total do fetiche. Está ali, aqui, agora, no cotidiano, se fazendo por ele ao passo que é moldado pelo próprio cotidiano. Por isso mesmo o equívoco de considerar o debate ambiental enquanto desprovido de ideologia e processos historicamente instituídos. O privilégio do dinheiro e a tirania que é adotada para a manutenção do presente paradigma econômico e social devem ter dimensões centralizadas no que corresponde o esforço de se debruçar acerca do ambiente e seu regimento pela evolução das técnicas e das normas jurídicas, difundidas pelo Estado e outros agentes econômicos.

O privilégio à lógica de mercado, à racionalidade econômica, se fundamenta enquanto característica primordial da formulação do atual modelo civilizatório, assentado na lógica desenvolvimentista que garante a produção da riqueza concentrada. Para esse sistema se sustentar, é necessária uma gama de relações complexas articuladas por redes, em escalas variadas, onde a política exerce fundamental protagonismo para a manutenção do atual paradigma da globalização, em que os espaços tendem a se adaptar cada vez mais as normas e formas impostas. Com relação ao regime político e jurídico que sustentam o motor da máquina capitalista no tempo presente, Santos (2006, p. 169) afirma que

A dinâmica dos espaços da globalização supõe uma adaptação permanente das formas e das normas. As formas geográficas, isto é, os objetos técnicos requeridos para otimizar uma produção, somente autorizam essa otimização ao preço do estabelecimento e da aplicação de normas jurídicas, financeiras e técnicas, adaptadas às necessidades do mercado. Essas normas são criadas em diferentes níveis geográficos e políticos, mas as normas globais, induzidas por organismos supranacionais e pelo mercado, tendem a configurar as demais. E as normas de mercado tendem a configurar as normas públicas. Assim, graças à competitividade, a tendência atual ao uso das técnicas e à implantação dos respectivos objetos, tende a ser ainda mais anárquica do que antes.

À primeira vista, em leitura simplista, poderíamos dizer que temos muito a comemorar, pois a revolução da técnica propiciou grandes mudanças no processo produtivo, proporcionando números e cifras nunca imaginadas. Mas desse sistema o aprofundamento das desigualdades nasce como a cabeça cortada da Hidra de Lerna (da mitologia grega), a 
concentração de riquezas é parte constitutiva de todas as relações assentadas na égide do capitalismo. A natureza é tomada como propriedade privada, a água e a terra, apenas recursos que visam o aumento dos índices do sistema econômico, tornam-se mercadorias. O outro, humano, homem e mulher, se tornou massa, conjunto genérico ligado à produção e ao dinheiro, massa de mão-de-obra; posto em condições precárias, subalternizado, massa de mão-de-obra barata; digno apenas do mínimo, salário, sal, troca justa (?). E se não trabalha, se não produz e não contribui com o sistema pelo o aumento da riqueza dos poucos, perde a sua humanidade, o seu direito de ser humano, homem e mulher; deixa de ser cidadão, proibido de tomar decisões no conjunto da polis.

Por meio de leitura mais profunda, vemos que não temos muito do que nos orgulharmos, estamos diante de uma crise, mas não é uma crise da natureza, corroboramos com Leff $(2008$, p. 17) quando afirma que "a degradação ambiental se manifesta como sintoma de uma crise de civilização, marcada pelo modelo de modernidade regido pelo predomínio do desenvolvimento da razão tecnológica sobre a organização da natureza".

Santos (2006, p. 170) nos alerta que a interpretação da crise ecológica "não pode ser feita sem levar em conta, mais uma vez, a tipologia dos objetos técnicos e as motivações de seu uso no presente período histórico", ou seja, não podemos deixar de entender o quadro polissêmico em que se enquadra o conceito e os usos sobre o ambiente na contemporaneidade, sendo tomado como recurso financeiro, permeado pelos objetos, as normas e as técnicas para o processo finalístico voltado à exploração.

A ideologia da natureza estabelecida nesses moldes se apresenta em categorias desarticuladas, apesar de ser consolidada na totalidade de um amplo, complexo e articulado campo. Vide algumas preposições exploradas e consideradas nos termos da ideologia da natureza (SMITH, 1988), na globalização da natureza e na natureza da globalização (PORTOGONÇALVES, 2006). Exemplos de esforços teóricos que conduzem a um caminho que privilegia a dimensão da totalidade do meio ambiente ao que está posto na imbricação da política, da economia, da cultura, das relações sociais em geral.

Tais linhas foram escritas para traduzir a humildade proposta aqui, a de partir de uma filosofia da socionatureza considerando a imanente crise socioambiental para a afirmação de um processo que busca a construção que considera cada vez mais o âmbito da transformação.

Lefebvre em sua obra "A vida cotidiana no mundo moderno" parte em atacar o cotidiano partindo da filosofia, e utilizamos suas referências metodológicas justamente por estar considerando que a filosofia 
reata as reflexões fragmentárias e os conhecimentos parcelares. Impossível fazer abstração da filosofia como pesquisa sobre o homem (essência e existência), sobre o conhecimento (verdadeiro ou falso), sobre o possível e o impossível. Não há outra referência para se apreciar e pôr em conexão os elementos e fragmentos descobertos (LEFEBVRE, 1991, p. 17)

Cotidiano e meio ambiente, entendendo aqui a máxima da realização dos seus processos, quando postas de forma associadas na compreensão da vida, considerando as preposições de Lefebvre, conduzem e devem se dirigir a reatar as reflexões fragmentárias e os conhecimentos apresentados parcelares, de forma a fomentar esse exercício de conexão dos elementos. Posta a discussão, compreendemos que deve ser dado o rigor com o tratamento dos processos de injustiça socioambiental no âmbito teórico-metodológico levados ao movimento da vida cotidiana, que em sua riqueza e miséria expressam os graus incisivos da socionatureza, conjecturando em determinadas abordagens o que se considera pela formulação de meio ambiente.

Mas um cuidado deve ser tomado na interpretação sobre a nossa proposta enunciada, considerar o conceito de cotidianidade e suas relações não é partir de sua defesa para a manutenção da mesma, mas sim, a partir dele, formular categorias renovadas que tensionam as relações postas para um novo quadro de sociabilidade, de percepções e ideologias. O que se exprime é a transformação do cotidiano, como afirma Lefebvre (1991, p. 19):

O conceito de cotidianidade provém da filosofia e não pode ser compreendido sem ela. Ele designa o não-filosófico para e pela filosofia. Mas o pensamento só pode levá-lo em consideração no decorrer de uma crítica da filosofia. O conceito de cotidianidade não vem do cotidiano nem o reflete: ele exprime antes de tudo a transformação do cotidiano vista como possível em nome da filosofia.

Em seguida, o autor supracitado discorre de forma mais aprofundada sobre as especificidades do cotidiano, que nos subsidia a entender melhor algumas categorias e nuances. O cotidiano enquanto conjunto de atividades "em aparência modestas, como conjunto de produtos e de obras bem diferentes dos seres vivos" não seria apenas o que escapa aos mitos da natureza, do divino e até mesmo do humano. E de forma enfática, não estaria se debruçado à determinação da subjetividade dos filósofos ou a representações objetivas de objetos, que Lefebvre exemplifica com roupas, alimentação, mobília, entre outros. Mas então, em que consiste o cotidiano? 
[Em] um campo e uma renovação simultânea, uma etapa e um trampolim, um momento composto de momentos (necessidades, trabalho, diversão produtos e obras - passividade e criatividade - meios e finalidade etc.), interação dialética da qual seria impossível não partir para realizar o possível (a totalidade dos possíveis) (LEFEBVRE,1991, p. 20).

Nossa perspectiva vem acrescida que na totalidade dos possíveis há de se considerar os momentos de tensão, materializados em diferentes graus de violências (materiais e imaterais, simbólicas) que se fazem na rotina diária que confere a reprodução do espaço, e em nossa abordagem, que também se refere à reprodução da socionatureza, pois o grau de violência não se limita à exploração do humano, mas em rotina de expropriação da natureza via exploração e produção de injustiças com diversas populações.

Aqui, no cotidiano, conta e comporta diversas possibilidades e planos, sonhos e pesadelos, encantos e desencantos, do passivo ao ativo e do ativo ao passivo dos viventes e pensantes. E Lefebvre (1991, p. 27) pontua:

No entanto, essas pessoas nascem, vivem e morrem. Vivem bem ou mal. E no cotidiano que eles ganham ou deixam de ganhar sua vida, num duplo sentido: não sobreviver ou sobreviver, apenas sobreviver ou viver plenamente. É no cotidiano que se tem prazer ou se sofre. Aqui e agora.

Mas como se constitui essa vida? O que engendra esses processos que resultam nas atividades e referenciais postos? Perguntas que podem ser colocadas para questionarmos a relação socionatureza que se apresenta. Lefebvre abre caminhos relacionando a vida cotidiana com o paradigma da modernidade, atentando que no estudo da vida cotidiana temos subsídios que oferem um ponto de encontro para as "ciências parcelares", e acrescentamos que no que se refere aos estudos sobre a natureza, as ciências expressaram na evolução de seus caminhos profundas ambiguidades, contradições e divergências (nas ciências sociais, biológicas e a própria Geografia). O movimento que incide certa tensão está na formulação das prerrogativas do método científico que consolidou a especialização e a fragmentação do saber, que postulou a racionalidade sobre a qual o sistema capistalista se assentou. Mas o cotidiano revela o encontro,

Mostra o lugar dos conflitos entre o racional e o irracional na nossa sociedade e na nossa época. Determina assim o lugar em que se formulam os problemas concretos da produção em sentido amplo: a maneira como é produzida a existência social dos seres humanos, com as transições da escassez para a abundância e do precioso para a depreciação. Essa análise crítica seria estudo das opressões, dos determinismos parciais. Ela visa a 
virar pelo avesso esse mundo em que os determinismos e as opressões passam por racionais, ao passo que a razão sempre teve como sentido e fim o domínio dos determinismos. (LEFEBVRE, 1991, p. 30)

A importância e validade do cotidiano está posto nessa premissa: desenvolver uma racionalidade que refuta a ideologia disfarçada de razão e ciência que valoriza as opressões, a fragmentação e o imperativo que move as relações hegemônicas. Mas para tal, nos embasamos no que Lefebvre (1991, p. 30-31) mostra enquanto dois conjuntos de fatos ligados:

\begin{abstract}
A cotidianidade e a modernidade. Esta é uma auréola daquela e a encobre, ilumina e esconde. São as duas faces do espírito do tempo. Ao cotidiano, conjunto do insignificante (concentrado pelo conceito), responde $\mathrm{e}$ corresponde o moderno, conjunto dos signos pelos quais essa sociedade se significa, se justifica, e que faz parte da sua ideologia. [...] Ora, cada um deles, o cotidiano e o moderno, marca e mascara, legitima e compensa o outro. A vida cotidiana universal da época, segundo a expressão de Hermann Broch, é o inverso da cotidianidade, é o espírito do tempo. Seus aspectos ou facetas são, a nosso ver, tão importantes quanto o terror atômico e a conquista do espaço.
\end{abstract}

O moderno, qualificado como o conjunto dos signos pelos quais a nossa sociedade se significa e se justifica, justificando as práticas, os atos, as ideologias, as que promovem e consolidam o aprofundamento da desigualdade (âmbito geral), que se espraia ao (falso e/ou efetivo) domínio de todos a cada dia, a cada conversa no ônibus, trem ou metrô cheio na volta para casa depois de um dia cansativo de trabalho; nas mensagens trocadas pelos aplicativos que tornaram cada vez mais instantâneo o fluxo de informações; na mesa do bar; na conversa desencadeada na fila para o banco; na pausa do almoço após uma manhã árdua de sol quente no verão; no culto de domingo à noite, onde há um núcleo pulsante de sociabilidade e um dado acolhimento das pessoas por parte crenças e concepções da vida e da morte; nas orações antes de dormir que expressam a gratidão pela vida, a comida, a saúde e pela dádiva do trabalho, mesmo sendo esse que sequestra o homem de sua liberdade e emancipação, condicionado no/pelo trabalho a sofrer no corpo as contradições imanentes do atual período histórico.

E claro, também consideramos os gestos, atos simples e complexos que surgem ao enfrentamento do que está sendo posto, pelo movimento dialético, desencadeados pelas resistências garantidas pela existência de determinados grupos e sujeitos, que exemplificam que nosso sistema (que gere suas infindáveis crises) não é o caminho único e progressivo manisfestado pela relação e exploração de homens sobre homens e sobre a natureza. $\mathrm{O}$ 
cotidiano e o moderno, as faces da realidade que expressam a sociedade em que vivemos, que se significam reciprocamente, bem como elabora Lefebvre. E no teor da discussão que propomos, faz-se de suma importância a busca sobre como a ideologia da natureza se produziu e produz ao longo da modernidade, que legitima e justifica os signos da exploração e expropriação manifestadas no/pelo cotidiano, em disputadas de imaginários, de poder/saber, de cosmovisões. Nos falta espaço nessas linhas que devem ser limitadas para articular de forma mais profunda tal discussão, mas deixamos as propostas de leitura para aprofundamento (PORTO-GONÇALVES, 1989, 2006; QUIJANO, 2005; DUSSEL, 2005; CASTRO-GÓMEZ, 2005; MIGNOLO, 2008; ESCOBAR, 2015; CRUZ, 2017)

O marco histórico da modernidade, conjuntamente com o colonialismo, é levantado como a convergência da revolução das ideias científicas, tecnológicas e filosóficas basilares para as concepções que legitimam ideologicamente os processos de expropriação e produção sobre a natureza e de sociedades outras, que não a moderna, juntamente com seus saberes. Com base em Rua (2007, p. 144), entendemos a complexidade do processo, pois além de modernização, progresso e desenvolvimento são termos "intercambiáveis e têm marcado o movimento do todo social como projeto civilizatório no Ocidente, e, paulatinamente, ao se tornar hegemônico, tal projeto, foi sendo imposto a todos os quadrantes do mundo". O autor pontua (2007, p. 149):

Então, pode-se dizer que modernização, como base concreta da modernidade, teve como conceito-gêmeo o progresso, e a ambos foi, após a Segunda Guerra Mundial, acrescentado o conceito-síntese de desenvolvimento, que passou a expressar aquela base concreta. Evolucionista, como os anteriores, de caráter sempre positivo, como os dois conceitos que o têm acompanhado (progresso e modernização), o desenvolvimento tem se mostrado ainda mais forte ideologicamente. Além do caráter positivo e evolucionista, sintetiza, também, um projeto civilizatório ocidental que o coloca como instrumento operativo de um paradigma a ser seguido por todos os modelos de sociedade.

Modernidade, progresso e desenvolvimento são temos bases para entender a forma intelectual e relacional atribuída aos significados acerca de natureza, consolidada por processos dialéticos e complexos que envolvem as relações entre a economia, a política e a cultura (modos de ser, conceber, sentir e produzir). O conceito de natureza não é natural, expressa uma dimensão articulada por diversos componentes inter-relacionados, ou seja, é um significado que deve ser tratada como relacional, sendo concebida, (re)organizada e estruturada pelo movimento histórico-geográfico nas/pelas relações sociais, pela promoção da 
evolução das técnicas, intermediadas com o discurso moderno. Segundo Porto-Gonçalves $(1989$, p. 23),

Toda sociedade, toda cultura cria, inventa, institui uma determinada ideia do que seja a natureza. Nesse sentido, o conceito de natureza não é natural, sendo na verdade criado e instituído pelos homens. Constitui um dos pilares através do qual os homens erguem as usas relações sociais, sua produção material e espiritual, enfim, a sua cultura.

Nesse sentido, as bases da organização humana têm na natureza sentidos muito mais íntimos e amplos, Marx já afirmava que "a vida humana depende da eterna necessidade de mediação do metabolismo entre homem e natureza" (MARX, 2013, p. 167), mediação dada pelo caráter ontológico do trabalho, ou seja, o homem se relaciona, muda e transforma a natureza pelo trabalho (atividade, ação), ao mesmo passo que também se transforma. É um processo que envolve não apenas a busca pelas condições materiais de existência, mas, igualmente, formulações relacionadas à autocriação humana e de elaboração do seu entorno (o externo, para além do corpo).

Smith (1988) também discorre sobre alguns aspectos da ideologia da natureza para elaborar a sua teoria do desenvolvimento desigual sob a égide do sistema capitalista, para ele o conceito de natureza é um produto social que expressa funcionalidades sociais e políticas, um conceito extremamente complexo e contraditório, permeado por concepções dualistas (a natureza exterior e a universal). Na evolução do pensamento científico (dado na era moderna), implicado com o desenvolvimento das forças produtivas, a partir de Bacon, tornou-se comum o tratamento da natureza como exterior.

No processo de trabalho, os seres humanos tratam os materiais naturais como objetos exteriores de trabalho a serem transformados em mercadorias. Os produtos põem as "artes mecânicas" entre si mesmos e os objetos de trabalho. E se a ciência vai funcionar como um meio de desenvolver essas "artes mecânicas", então ela também deve tratar a natureza como um objeto exterior (SMITH, 1988, p. 32)

Mais que isso, ora a natureza como objeto exterior (o que justifica sua dominação), ora a natureza romântica e poética, a paisagem (fornecendo modelos para o comportamento social), esse processo que Smith (1988, p. 45) chama de "a ideologia da natureza", que para ele não é simplesmente um conjunto de ideias erradas, mas é um conjunto de ideias 
"radicadas na experiência prática, embora seja a experiência prática de uma dada classe social que vê a realidade através da sua própria perspectiva e, ainda assim, de forma parcial”.

Smith tece importantes considerações que versam sobre a geografia da política e a política da geografia considerando a reestruturação do espaço geográfico pelo capital, designando que o desenvolvimento desigual é marca característica, princípio, da geografia do capitalismo. O desenvolvimento desigual é a "expressão geográfica sistemática das contradições inerentes à própria construção e estrutura do capital" (SMITH, 1988, p. 16), contradição fundamental entre valor de uso e valor de troca. Esse padrão é refletido pelo campo de disputas em que se exerce a apropriação da natureza, por isso afirmar que no âmbito dos processos de injustiça e segregação socioambinetal, a geografia tem papel de suma importância para as análises e propostas de intervenção frente à conjuntura. Pedimos desculpas e licença ao leitor e leitora para o uso de uma citação mais longa, mas que julgamos necessário pela máxima do argumento trazido pelo autor que elucida e enlaça o presente ensaio:

\begin{abstract}
A produção do espaço, de fato, é posta como premissa sobre um processo de produção mais básico ainda, que pareceria ainda mais quixotesco e que abala nossa tradicional aceitação daquilo que até aqui parecia evidente por si mesmo. A produção da natureza não somente oferece um fundamento filosófico para se discutir o desenvolvimento desigual do capitalismo, mas é um resultado muito real do desenvolvimento desse modo de produção. [...] Em sua tendência constante para acumular quantidades cada vez maiores de riqueza social sob seu controle, o capital transforma a face do mundo inteiro. Nenhuma pedra feita por Deus permanece inalterada, nenhum ser vivo deixa de ser afetado. Em consequência, os problemas da natureza, do espaço e do desenvolvimento desigual são colocados juntos pelo próprio capital. O desenvolvimento desigual é o processo e o padrão concreto da produção da natureza sob o capitalismo (SMITH, 1988, p. 20).
\end{abstract}

Posta a articulação da produção do espaço e da natureza, o princípio filosófico que rege a compreensão sobre tais conceitos deve estar articulado a uma noção revolucionária, pela busca de referenciais inéditos, ou seja, uma filosofia que se exerce na prática diária. A revolução do cotidiano para além da generecidade e a banalidade. O desenvolvimento desigual se materializa em diversas escalas e comprende a produção e segregação socioespacial, o que se relaciona à segregação socioambiental. Valorizar o cotidiano parte da noção profunda de reconhecimento das formas como se implantam os signos e as ideologias da crise societária (ecológica). 
Com escrita articuladora para esse debate, Rua (2008, p. 9) traz ao debate Soja, Smith e Harvey para afirmar que a concepção de desenvolvimento geográfico desigual contém a fusão de dois elementos que podem nos oferecer subsídios analíticos: a mudança das escalas e a produção das diferenças geográficas. Elementos resultantes da: aproximação e combinação dos momentos e das fases distintas “do amálgama de formas 'arcaicas' e 'modernas', das interações espaciais em suas dimensões materiais e imateriais, desiguais e contraditórias, que marcam um determinado território".

Tais diferenças levam o autor supracitado a designar os desenvolvimentos geográficos desiguais (plural, teor da multiciplidade-singularidade), caminho que se abre para a reformulação sobre o teor das sustentabilidades (múltiplas, abertas, contraditórias, territorializadas) e o papel da geografia enquanto base analítica para novos direcionamentos que envolvem a construção autônoma e participativa dos sujeitos concretos, concepção para além da promulgada pelo desenvolvimento sustentável, formulada em termos práticos e discursivos pelo privilégio da lógica economicista de desenvolvimento que "é atrelada a uma visão restritiva e de desenvolvimento e de território e as políticas a ela dirigidas continuam tributárias das políticas neoliberais” (RUA, 2008, p. 10). Essa perspectiva tenta

enfatizar as particularidades e singularidades de cada formação econômicosocial, em suas múltiplas escalas, mas integrada à lógica mais geral do capitalismo, em outras escalas. É nesses lugares, onde vivem os sujeitos concretos, em sua singularidade individual e social, que se vão explicitar, segundo nosso ponto de vista, as sustentabilidades múltiplas, abertas, contraditórias, territorializadas (RUA, 2008, p.9).

A elaboração crítico-filosófica da dimensão do cotidiano pode ser usada como metodologia interpretativa da realidade, um enfoque que pode complementar ainda mais a noção de sustentabilidades desenvolvida pelo professor Rua $(2008$, p. 12), esta que só pode ser atribuída às âncoras espaciais.

Para nós as sustentabilidades têm uma âncora territorial muito marcante quando percebidas como um processo pelo qual as sociedades, integradas a escalas variadas, superpostas mas interatuantes, administram suas condições materiais e imateriais, redefinindo os princípios éticos e sociopolíticos que orientam as suas diferentes formas de (re)construir e relacionar-se com o seu(s) território(s).

A perspectiva ontológica do território articula as rupturas e renovações necessárias para o privilégio da dimensão da vida cotidiana, que não se restringe à escala local, pois a própria vida não é restritiva e seria um grande equívoco conceitual tal restrição ao enfoque 
cotidiano, esse que é aberto, integrado a escalas variadas denotando diferentes formas de apropriação, dominação e articulação de poderes, processos, fenômenos e interações expressadas pela a dupla conotação do território, material e simbólica (HAESBAERT, 2007). Território é um conceito chave para o prosseguimento da consolidação da proposta de regeneração do conceito de sustentabilidade.

A noção de sustentabilidade territorial muito pode convergir e se relacionar com a perspectiva de territórios alternativos de Haesbaert (2002). Sustentabilidade territorial parte de uma perspectiva ancorada na relação entre construção da autonomia com o reforço da identidade e do respeito à alteridade, o que permeia a valorização de características culturais particulares em diversas escalas. Sustentabilidade que daria bases a um "desenvolvimento e a uma sustentabilidade interagentes e únicos em suas combinações, autocentrados mas participantes das diversas escalas da ação política” (RUA, 2008, p. 13).

É dada ênfase à multiescalaridade da ação política, que denota princípios particulares e ao mesmo tempo abrangentes de projetos revolucionários para a busca de novas ordenações territoriais, o que Haesbaert (2002, p. 15) designa como os territórios alternativos, para ele,

Ao lado de uma geopolítica global das grandes corporações brotam 'micropolíticas' capazes de forjar resistências menores - mas não menos relevantes -, em que territórios alternativos tentam impor sua própria ordem, ainda minoritária e anárquica, é verdade, mas talvez por isso mesmo embrião de uma nova forma de ordenação territorial que começa a ser gestada.

Ou seja, partimos como pressuposto que o território é multimendisional, forjado pelas interações sociais permeadas por conflitos, disputas de poder e articulações, que são integradas pelas sustentabilidades territoriais, permitindo a construção e vivência de superpostas e justapostas diversas perspectivas de sustentabilidades, com base na autonomia ativa, que pressupõe a participação ativa e consciente dos indivíduos pertencentes a uma comunidade, "para levar a uma gestão democrática do território onde não haja excluídos, onde o espaço banal, do acontecer cotidiano, seja um espaço de comunhão, de comunicação, enfim, um lugar de todos" (RUA, 2008, p. 13).

\section{Considerações finais}

O devir histórico, as produções dos desejos, as elaborações acerca da vida, da natureza, do desenvolvimento, do projeto societário moderno-capitalista, as indignações 
latentes, da imersão no cotidiano (dialético-contraditório), da passividade ao (esperado) projeto revolucionário para designar uma sociedade mais livre das correntes que aprisionam os corpos e as mentes, senão livre, que possa, enquanto processo, desvelar a realidade para as correntes ficarem visíveis. A vida cotidiana é a vida de todo homem (HELLER, 1985), comporta os anseios, as paixões, as aspirações, a conformidade, o sentido da vida, a socionatureza em realização e reelaboração constante, de todos e todas, o espaço banal (SANTOS, 1996).

Com humildade e intenção criativa, tentamos articular tais noções para aprimorar ainda mais o movimento de busca da regeneração do conceito de sustentabilidade, aqui, sendo regido (mas sem simplificação) por uma dimensão, a da vida comum. Não fizemos a defesa da escala local, pontuamos a defesa da valorização de uma dimensão que agrega a multiescalaridade e a transescalaridade, a justaposição e o movimento complexo da realidade, não apenas restringido ao global, ao nacional, ao regional e ao local.

Complexidade que é atribuída à discussão da já caracterizada geografia ambiental (SOUZA, 2018), apreendida por nós pela a noção-enfoque (e não um conceito) de socionatureza (SWYNGEDOUW, 2001), que muito tem a contribuir para rumos renoavados para padrões de desenvolvimentos que privilegiam as singularidades territoriais e o poder de mobilização dos sujeitos, capazes de articuçalões abertas, múltiplas e contraditórias pela a defesa da vida, das sustentabilidades.

\section{Referências}

CASTRO-GÓMEZ, S. Ciências sociais, violência epistêmica e o problema da "invenção do outro". In LANDER, E. (org). A Colonialidade do saber: eurocentrismo e ciências sociais, Perspectivas latino-americanas. Colección Sur Sur, CLACSO, Ciudad Autónoma de Buenos Aires, Argentina. 2005.

CRUZ, V. C. Geografia e pensamento descolonial: notas sobre um diálogo necessário para a renovação do pensamento crítico. In CRUZ, V. C.; OLIVEIRA, D. A. (orgs). Geografia e giro descolonial: experiências, ideias e horizontes de renovação do pensamento crítico. Rio de Janeiro: Letra Capital, 2017. p. 37-54.

DUSSEL, E. Europa, modernidade e eurocentrismo. In LANDER, E. (org). A Colonialidade do saber: eurocentrismo e ciências sociais, Perspectivas latino-americanas. Colección Sur Sur, CLACSO, Ciudad Autónoma de Buenos Aires, Argentina. 2005.

ESCOBAR, A. Territórios da diferença: a ontologia política dos "direitos ao território".

Desenvolvimento e Meio Ambiente, v. 35, 2015. 
HELLER, A. O cotidiano e a história. Paz e Terra: Rio de Janeiro, 1985.

LAYRARGUES, P. P. A Natureza da ideologia e a ideologia da natureza: elementos para uma sociologia da educação ambiental. Tese de doutorado apresentada ao departamento de sociologia do Instituto de filosofia e ciências humanas da Universidade Estadual de Campinas, 2003.

LEFF, E. Saber Ambiental: Sustentabilidade, racionalidade, complexidade, poder. $6^{\circ}$ ed.Petrópolis, RJ: Vozes, 2008.

LEFEBVRE, H. A vida cotidiana no mundo moderno. Editora Ática, São Paulo, 1991.

LEFEBVRE, H. La Conscience mystifiée. Suivi de La Conscience privée. Paris: Syllepse, 1999 [1936].

MARX, K. O capital: crítica da economia política. Livro I: o processo de produção do capital. Editora Boitempo, 2013.

MIGNOLO, W. Desobediência epistêmica: a opção descolonial e o significado de identidade em política. Cadernos de letras da UFF - Dossiê: Literatura, língua e identidade, $\mathbf{n}^{\circ}$ 34, p. 287-324, 2008.

PORTO-GONÇALVES, C. W. A globalização da natureza e a natureza da globalização. Rio de Janeiro: Civilização Brasileira, 2006.

PORTO-GONÇALVES, C. W. Os (des)caminhos do meio ambiente. São Paulo: Contexto, 1989.

QUIJANO, A. Colonialidade do poder, eurocentrismo e América Latina. In LANDER, E. (org). A Colonialidade do saber: eurocentrismo e ciências sociais, Perspectivas latinoamericanas. Colección Sur Sur, CLACSO, Ciudad Autónoma de Buenos Aires, Argentina. 2005 .

RUA, J. Desenvolvimento, Espaço e Sustentabilidades. IN: RUA, J. (org.). Paisagem, Espaço e Sustentabilidades. Rio de Janeiro: PUC-Rio, 2007;

RUA, J. Desenvolvimentos e sustentabilidades: uma perspectiva geográfica. In:

OLIVEIRA, M. P. COELHO, M.C.N. CORRÊA, A, M. O Brasil, a América Latina e o Mundo: Espacialidades Contemporâneas. Rio de Janeiro: Lamparina. 2008.

SANTOS, M. Por uma Geografia cidadã: por uma epistemologia da existência. Boletim Gaúcho de Geografia, Porto Alegre, AGB-EDIUPF, n. 21, p. 7-14, 1996.

SANTOS, M. A natureza do espaço. Técnica e tempo, razão e emoção. Ed. da Universidade de São Paulo. 2006.

SMITH, N. Desenvolvimento Desigual. Bertrand, Rio de Janeiro, 1988.

SOUZA, M. L. Quando o trunfo se revela um fardo: reexaminando os percalços de um campo disciplinar que se pretendeu uma ponte entre o conhecimento da natureza e o da sociedade.

Geousp - Espaço e tempo, v. 22, n. 2, p. 274-308. 2018. 
MARTINS, G. S.

SWYNGEDOUW, E. A cidade como um híbrido: Natureza, sociedade e "urbanizaçãociborgue". In ACSELRAD, Henri. A duração das cidades: Sustentabilidade e risco nas políticas urbanas. Ed. Lamparina, 2001. p. 99-120.

VESENTINI, J. W. Geografia, natureza e sociedade. São Paulo: Contexto, 1992.

\section{Agradecimentos}

À Coordenação de Aperfeiçoamento de Pessoal de Nível Superior (CAPES) pela a bolsa concedida para a realização do Mestrado. 